\title{
Copper coating of carbon steel by a furnace brazing process using brass as the braze
}

\author{
F. Molleda ${ }^{a}$, J. Mora ${ }^{a}$, J.R. Molleda ${ }^{b}$, E. Carrillo ${ }^{a}$, E. Mora ${ }^{a}$, B.G. Mellor ${ }^{c}$ \\ ${ }^{a}$ Escuela Técnica Superior de Ingenieros Navales de Madrid (UPM), Spain \\ ${ }^{b}$ Universidad Complutense de Madrid, Spain \\ ${ }^{c}$ University of Southampton, UK
}

\begin{abstract}
A ship building grade of carbon steel has been coated with copper by a furnace brazing process starting from a brass braze. An argon protective atmosphere was used to prevent oxidation of the steel. However, when the deposit was produced a low gas flow rate ensured that zinc was lost from the brass by oxidation leaving a copper deposit on the steel surface. The copper was found to be zinc free by Energy Dispersive X-ray spectroscopy. A metallographic study was carried out on the coated material and X-ray maps were used to identify the phases present in the coating. Diffusion was shown to play an important role in the development of the coating.
\end{abstract}

An industrial application of this kind of coating could be applied in the heat exchanger due to the good thermal conductivity of copper.

\section{Keywords}

Coatings, brazing, carbon steel, brass, metallography

\section{Introduction}

The purpose of this study is to prove that welding time influences the amount of Fe that dissolves within liquid $\mathrm{Cu}$ solution thereby affecting resistance to corrosion.

It is quite common that a structural material, such as a ship building grade of carbon steel, is coated with another material so as to provide another material property, for example wear or abrasion resistance, corrosion resistance and, in the present case better electrical and thermal conductivity [1,2]. However, one problem that often occurs with this type of coating is a low resistance to corrosion in certain environments. This means that the design of the bimetallic component must ensure that the interface between the two metals is not exposed to the environment [3].

To make the brazed joint no special preparation of the surfaces is necessary and no cleaning fluxes are required. The protective atmosphere is sufficient to prevent superficial oxidation. This makes the process particularly environmentally friendly as water is not used for removal of contaminants after bonding. Given that only the braze melts (note the filler material must melt at a temperature greater than $450^{\circ} \mathrm{C}$ to be called a braze) and not the base material and as the brazing is performed in a furnace where the temperature of the whole component is uniform, distortion is avoided as thermal gradients are not present in contrast to fusion arc welding processes. 


\section{$2 \quad$ Materials used}

Ship building grade A steel, of composition specified in Table 1, was used as the structural material. The microstructure of this material is presented in Fig. 1 and consists of ferrite and pearlite.

\begin{tabular}{|l|l|l|l|l|}
\hline $\begin{array}{l}\text { Chemical } \\
\text { composition }\end{array}$ & Carbon & Manganese & Phosphorous & Sulphur \\
\hline Weight \% & 0.23 max. & 0.56 min & 0.04 max. & 0.04 max. \\
\hline
\end{tabular}

Table $1 \quad$ Specified chemical composition of the structural carbon steel used.

The copper coating was achieved starting from a brass of composition $\mathrm{Cu}-61.3 \%$; $\mathrm{Zn}$ $38.7 \%$.

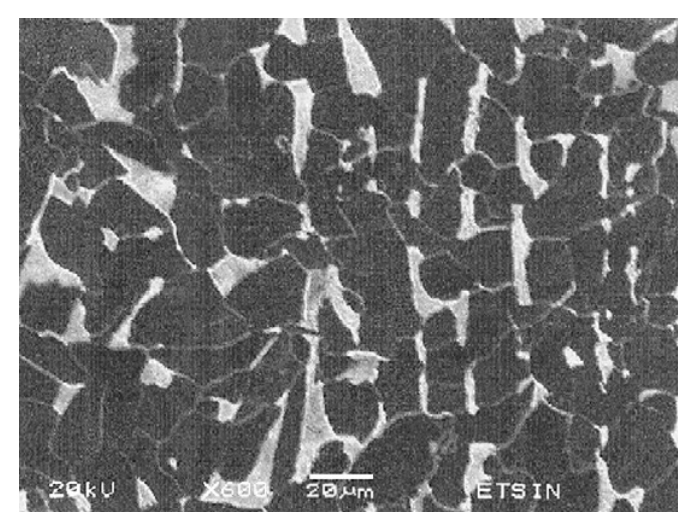

Fig. 1 Microstructure of the carbon steel.

\section{$3 \quad$ Furnace brazing}

The coating was carried out by preparing a vessel whose base was the carbon steel to be coated around which was welded a carbon steel tube so as to prevent loss of molten liquid once the melting temperature of the braze was reached. The brass braze was positioned in the interior of the vessel so constructed, Fig. 2.

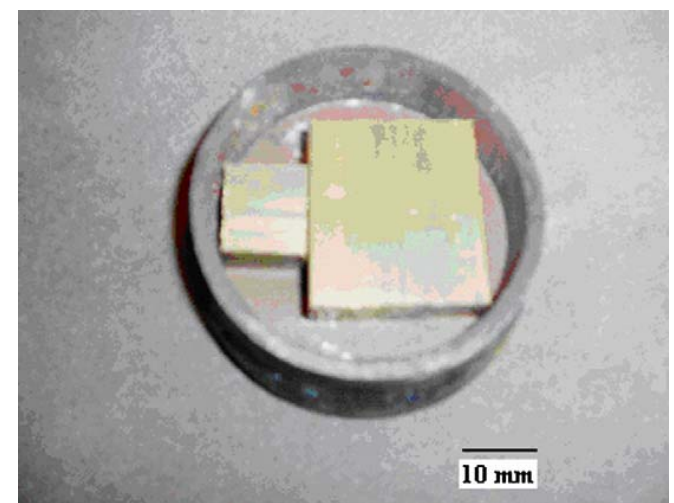

Fig. 2 Vessel prepared for brazing.

The vessel so prepared was positioned in a vertical resistance furnace (Fig. 3) and the temperature was raised to $1100^{\circ} \mathrm{C}$ to melt the brass. An argon lance was used to 
provide an inert atmosphere over the brazing area. However, the gas flow was set at a low rate $(12 \mathrm{l} / \mathrm{min})$ so that zinc was lost from the brass by oxidation. The final result was a copper deposit that did not contain zinc that was perfectly bonded to the structural material as can be seen in Fig. 4.

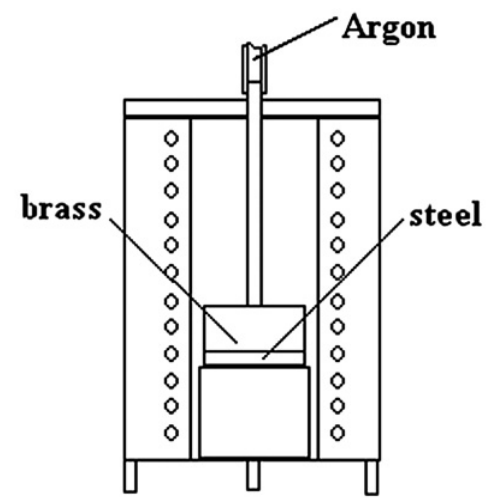

Fig. 3 Resistance furnace used for brazing.

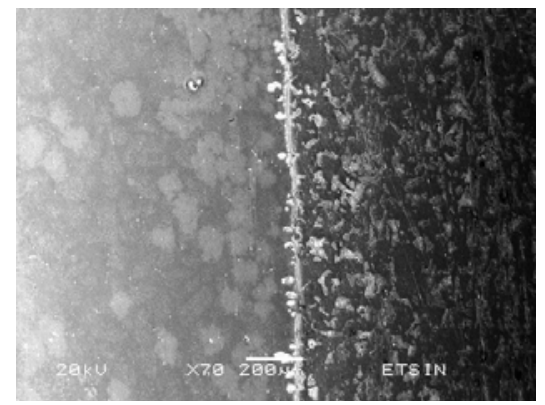

Fig. 4 Macrograph of the brazed material.

\section{$4 \quad$ Metallographic characteristics of the coating}

A transverse section through the coating was metallographically prepared, etched in $2 \%$ nital and examined in a scanning electron microscope. Detailed study of this sample indicated that this etch revealed iron rich dendrites in the copper coating (Figs. 5-8). Their chemical nature was confirmed by X-ray mapping (Figs 9 and 10). From the $\mathrm{Cu}-\mathrm{Fe}$ equilibrium phase diagram given in Fig. 11 it can be observed that iron will dissolve in liquid copper at the melting temperature $\left(1083^{\circ} \mathrm{C}\right)$ and has appreciable solubility. However, as the temperature falls the solubility decreases and this causes a segregation of iron in the copper matrix which accounts for the formation of the dendrites.

At the interface between the copper and the steel, the etch behaved much more aggressively as the copper and zinc gave rise to a galvanic couple. A region of copper diffusion was observed in the steel and confirmed by X-ray mapping. Penetration of copper along grain boundaries in the steel in contact with the copper was observed due to the high diffusion rates along such boundaries (Figs 12 and 13). 


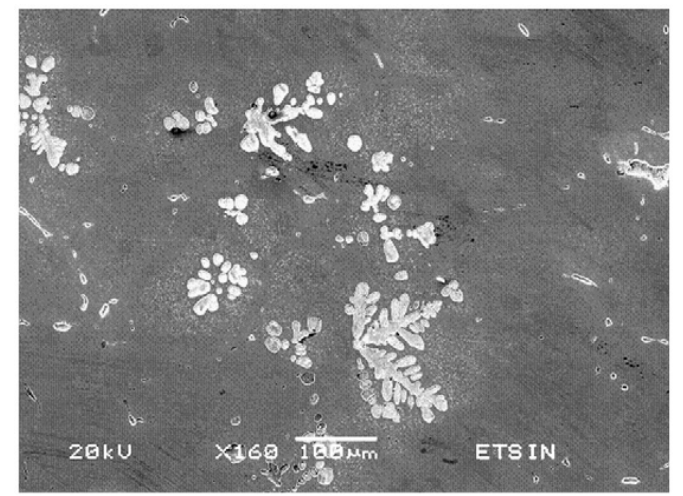

Fig. 5 Dendrites of iron segregated in the copper matrix.

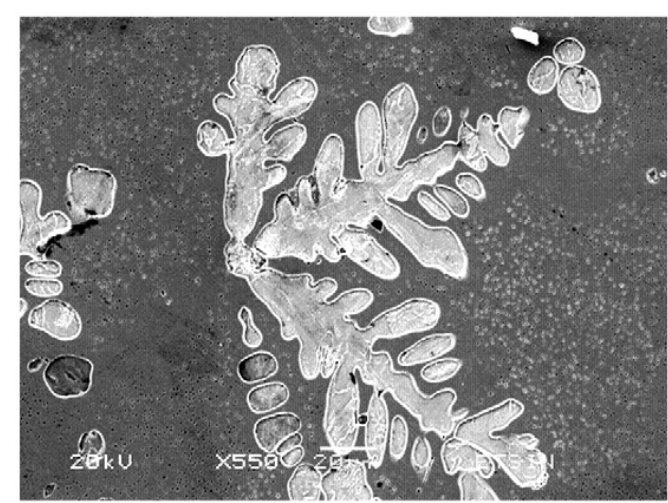

Fig. 6 Detail of Fig. 5 at higher magnification.

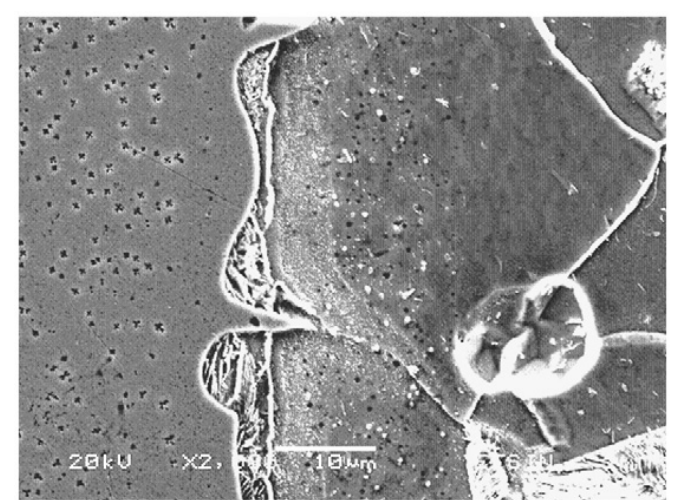

Fig. 7 Diffusion of copper along a grain boundary in the steel.

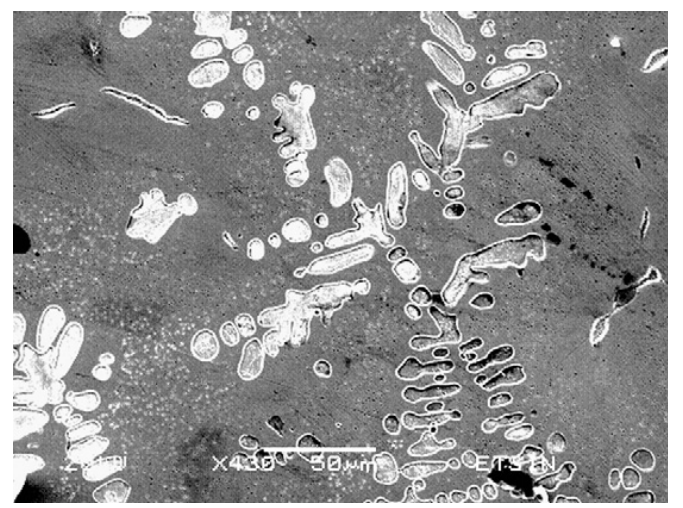

Fig. 8 Dendrites of iron segregated in the copper matrix. 


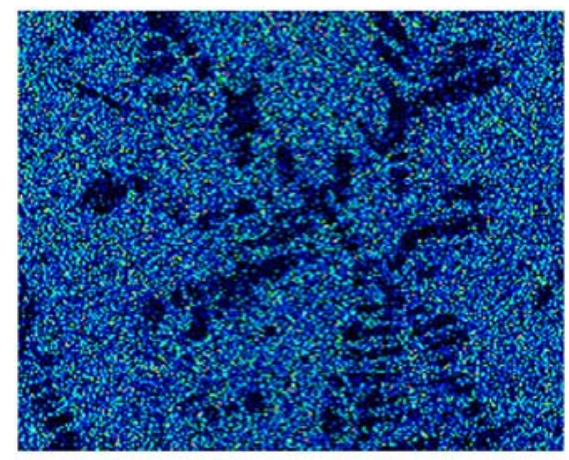

$100 \mathrm{~mm}$

Fig. 9 Copper X-ray map of the coating.

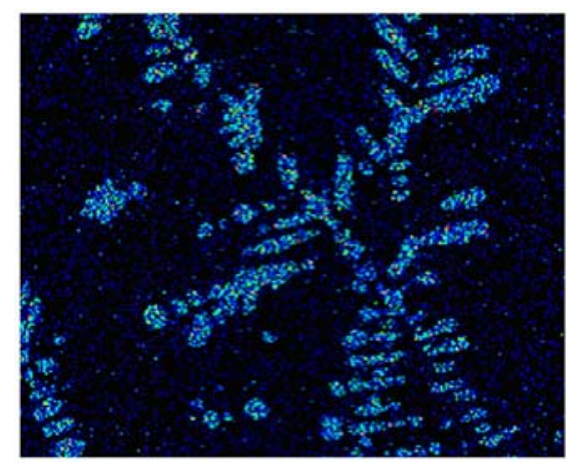

Fig. 10 Iron X-ray map of the coating.

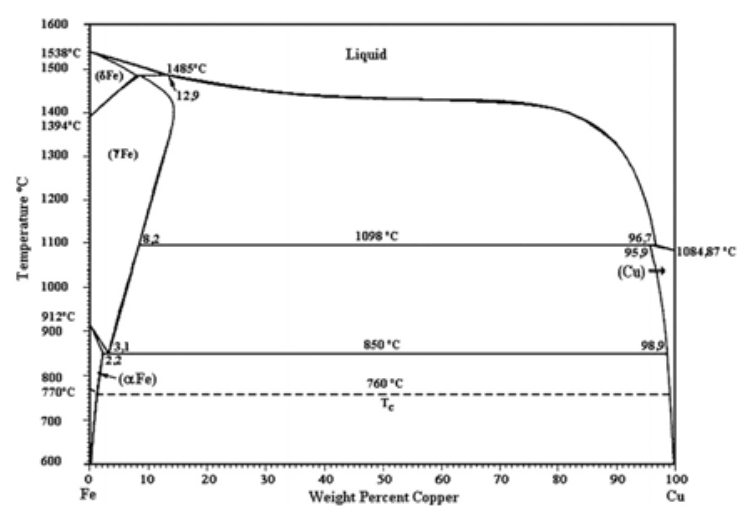

Fig. $11 \mathrm{Fe}-\mathrm{Cu}$ equilibrium phase diagram.

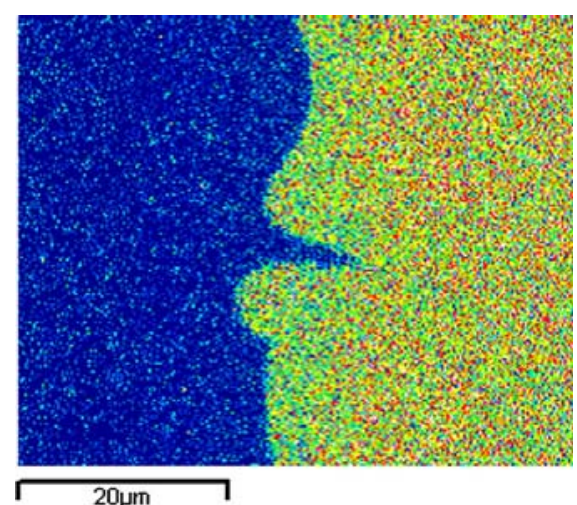

Fig. 12 Iron X-ray map showing the steel-copper interface. 
In addition to dendrites other forms of iron segregation were noted as seen in Figs 14 and 15. Iron appears to segregate preferentially along certain crystallographic planes in the face centred copper lattice.

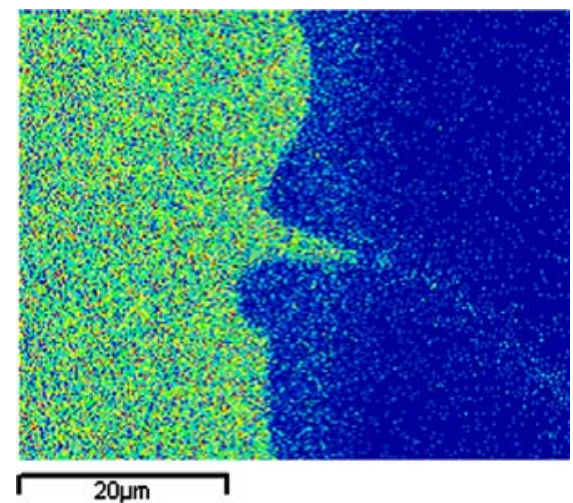

Fig. 13 Copper X-ray map showing the steel-copper interface. Note the diffusion of copper along a grain boundary in the steel.

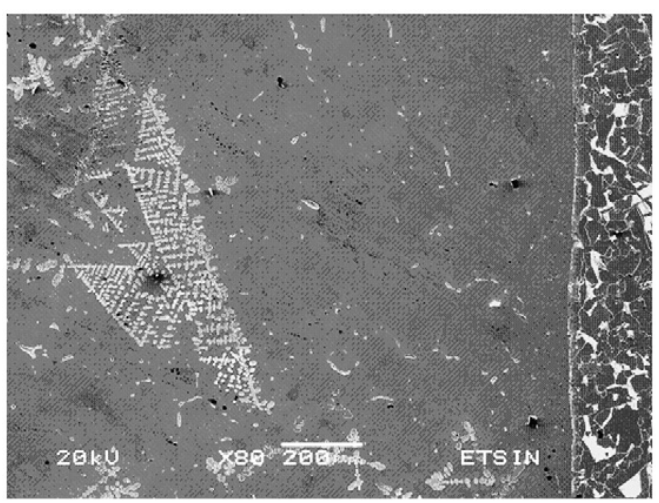

Fig. 14 Segregation of iron along certain crystallographic planes in the copper.

Fig. 14 indicates that the iron solid solution in the copper segregates far from the Fe$\mathrm{Cu}$ interface and that close to that interface no segregation was noted.

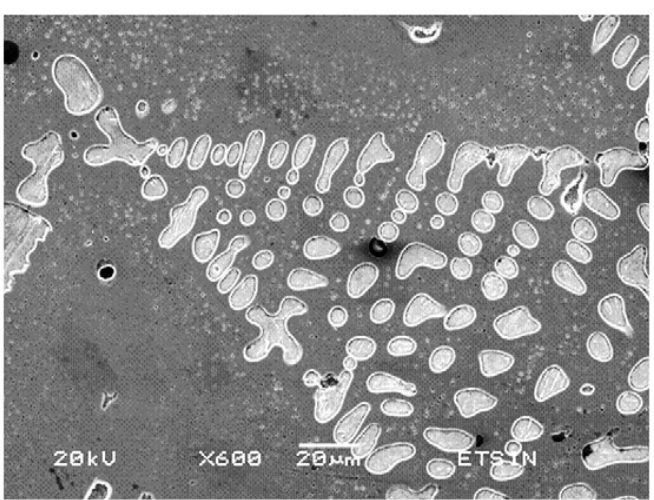

Fig.15 Detail of Figure 14 at higher magnification.

\section{Conclusions}

a. Furnace welding time favors the incorporation of Fe into liquid $\mathrm{Cu}$ solution.

b. During welding, $\mathrm{Cu}$ diffuses across the boundary grains of steel. 
c. At room temperature Fe shows a poor solubility and segregates from the $\mathrm{Cu}$ matrix. d. Segregation of Fe can explain the loss of corrosion resistance near the interface.

\section{$5 \quad$ Acknowledgements}

Acknowledgements are due to Jorge Agustín Quesada Ruiz for preparing the samples studied in the present paper.

\section{References}

$1 \quad$ Brazing Handbook, $4^{\text {th }}$ Edition, Miami, USA; American Welding Society; 1991. p 35-38 section XVII.

2 Peaslee Robert L. Brazing, yesterday's art has become today's science. Weld J 1992; 71 (10): 25-31.

3 Daniel Kay W. Ten reasons to choose brazing. Weld J, 2000; 79 (9): 3335. 